Table 1. Healthcare resource utilisation of patients with systemic lupus erythematosus between in Western Australia between 2000-2019.

\begin{tabular}{|c|c|c|c|}
\hline & Outpatient & ED Visits & Admissions \\
\hline Patients, n (\%) & $179(100)$ & $143(79.9)$ & $125(69.8)$ \\
\hline Total events, $n$ & 13,320 & 794 & 678 \\
\hline Visit rate per 100 patient years $(95 \% \mathrm{Cl})$ & $\begin{array}{c}738.9(726.3 \\
751.4)\end{array}$ & $\begin{array}{c}44.0(41.0 \\
47.2)\end{array}$ & $37.6(34.8,40.5)$ \\
\hline Patients with $\geq 2$ visit per annum, $n(\%)$ & $153(85.5)$ & 110() & $94(\%)$ \\
\hline Patients with $\geq 4$ visits per annum, $n(\%)$ & $112(62.6)$ & & \\
\hline Patients with $>10$ visits per annum, $n(\%)$ & $37(20.7)$ & $17(\%)$ & $13(\%)$ \\
\hline Discharged from ED, $\mathrm{n}(\%)$ & - & 684 & - \\
\hline Admitted from the ED, $\mathrm{n}(\%)$ & - & 110 & 110 \\
\hline Average length of stay, median (IQR) & - & $\begin{array}{c}3.0(2.1,4.0) \\
\text { hrs }\end{array}$ & $\begin{array}{c}3.2(1.5,5.85) \\
\text { days }\end{array}$ \\
\hline Patients with an overnight admission, $\mathrm{n}(\%)$ & & - & $122(98)$ \\
\hline Overnight admissions, median (IQR) & & - & $3(1,5)$ \\
\hline Patients with admissions $>7$ days & & - & $53(42.4)$ \\
\hline Costs AUD (FY2018/19) & $\$ 6,273,720$ & $\$ 869,430$ & $\$ 10,997,485$ \\
\hline
\end{tabular}

Acknowledgments: The authors wish to acknowledge the support of Arthritis Foundation of WA and Lupus WA

Disclosure of Interests: warren raymond: None declared, Georgia Ngo: None declared, Milica Ognjenovic: None declared, lan Li: None declared, Patrick Cheah: None declared, Aron Chakera: None declared, Andrew McLean-Tooke: None declared, Johannes ("Hans") Nossent Speakers bureau: Janssen DOI: 10.1136/annrheumdis-2020-eular.4219

\section{AB1185 $\quad$ BUDGET IMPACT ANALYSIS OF INTRODUCING SUBCUTANEOUS INFLIXIMAB CT-P13 SC FROM THE UK PAYER PERSPECTIVE}

M. Perry ${ }^{1}$, M. Jang ${ }^{2} .{ }^{1}$ Royal Alexandra Hospital, Paisley, United Kingdom;

${ }^{2}$ Celltrion Healthcare Co., Ltd, Incheon, Korea, Rep. of (South Korea)

Background: CT-P13 subcutaneous (SC) is the first and only SC version of infliximab developed by Celltrion Healthcare and currently approved by the European Medicines Agency (EMA) for the treatment of rheumatoid arthritis (RA). Infliximab has been only available in intravenous (IV) formulation and thus this new mode of administration will allow patients to self-inject at homes. Self-injection will reduce number of outpatient visits and expected to decrease IV administration cost significantly. This research describes the economic impact of introducing infliximab SC from the UK payer perspective.

Objectives: The budget impact analysis (BIA) was conducted to assess the financial impact of the adoption of infliximab SC. The BIA calculates the costs of treatment (drug acquisition cost and administration) for patients with RA as first-line treatments, and compares the cost in a scenario without infliximab SC vs a scenario with infliximab SC to estimate the budget impact over the 5 year period.

Methods: A prevalence-based BIM was developed incorporating epidemiological data, administration cost data from the literature and market share data from IQVIA. The analysis compared a market scenario where a proportion of patients were treated with infliximab SC ('World With' infliximab SC) to an alternative market scenario where infliximab SC were not available and all patients were treated with IV ('World Without' infliximab SC). The model assumed that the clinical outcomes are same between infliximab SC and infliximab IV, and patients entering the model were all naïve and remained in the treatment for 5 years. In the 'World With' scenario, patients receiving infliximab IV switched to SC administration at 30\% in Year 1, 45\% in Year 2 , and remained $60 \%$ from Year 3 to 5 . The drug cost of infliximab SC is assumed to be the same as that of comparator treatments. Administration cost per infliximab IV infusion was estimated to be £382 and £3.32 per SC administration.

Results: Compared to the "World Without" infliximab SC, the introduction of subcutaneous infliximab resulted in cost savings of £39.6 million in UK over a 5-year period, equating to 4,466 additional patients to be treated with infliximab SC in base case scenario.

Sensitivity analysis includes dose-escalation up to $5 \mathrm{mg} / \mathrm{kg}$ to reflect the realworld setting. In that scenario, the saving increases to $\$ 279.6$ million over a 5 -year period, equating to 30,839 additional patients to be treated with infliximab $\mathrm{SC}$.

Conclusion: Utilization of subcutaneous infliximab may lead to substantial cost savings for UK payers. Self-injection will significantly reduce the burden on healthcare delivery allowing resource to be spent elsewhere. Sensitivity analysis concluded that treatment with increased IV dose will result in higher savings from switching patients to subcutaneous infliximab.

\section{References:}

[1] European Medicines Agency. Remsima SC authorization details. https://www.ema.europa.eu/en/documents/product-information/ remsima-epar-product-information_en.pdf

[2] Carpenter, L., et al. (2014). Patients with Moderate Disease Activity in the First 5 Years of Rheumatoid Arthritis Still Progress Radiographically Despite Conventional Disease Modifying Therapy.: 2135. Arthritis \& Rheumatology 66.

[3] The NICE British National Formulary (BNF). https://bnf.nice.org.uk medicinal-forms/

[4] Tetteh, E. K., \& Morris, S. (2014). Evaluating the administration costs of biologic drugs: development of a cost algorithm. Health economics review, 4(1), 26.

[5] National Institute for Health and Care Excellence. (2016). Adalimumab, etanercept, infliximab, certolizumab pegol, golimumab, tocilizumab and abatacept for rheumatoid arthritis not previously treated with DMARDs or afte conventional DMARDs only have failed.

Disclosure of Interests: Martin Perry Grant/research support from: Grifols Abbvie, Sandoz unrestricted educational grant, Consultant of: Abbvie, Gilead, Celltrion Advisory Board, Speakers bureau: Sandoz, Minyoung Jang Employee of: HEOR \& Market access specialist in Celltrion Healthcare

DOI: 10.1136/annrheumdis-2020-eular.3422

\section{AB1186 THE NHS SCOTLAND THERAPEUTIC DRUG MONITORING SERVICE FOR BIOLOGIC MEDICINES: PRELIMINARY ANALYSIS OF UTILISATION AND CLINICAL RESULTS AT YEAR 1}

J. Macdonald ${ }^{1}$, M. Perry ${ }^{2}$, P. Galloway ${ }^{1}$, J. P. Seenan ${ }^{1}$, A. Dunlop ${ }^{1} .{ }^{1}$ Queen Elizabeth University Hospital, Glasgow, United Kingdom; ${ }^{2}$ Royal Alexandra Hospital, Paisley, United Kingdom

Background: Anti-tumour necrosis factor a (anti-TNFa) drugs infliximab (IFX) and adalimumab (ADL) are effective treatments for several rheumatic diseases. Therapeutic drug level and anti-drug antibody monitoring (TDM) has emerged as a useful tool for optimising drug effectiveness, by identifying individuals who may benefit from dose or treatment frequency adjustment, or have secondary drug failure due to immunogenicity.

Objectives: Ensuring safe and effective use of biologic medicines has been identified as a key priority for NHS Scotland. Inequity and inconsistency of access to TDM across the nation was recognised as a barrier to delivering best practice and so a nationally commissioned TDM service was proposed in January 2018 to support clinical practice, providing universal access to TDM for services treating inflammatory diseases across Scotland. Data collection and analysis of results regarding usage and clinical impact of the service were identified as key outcome measures to assess service success and sustainability.

Methods: A service webpage was developed to provide guidance on testing strategies and interpretation of TDM results (1). An automated search of clinical data and test results recorded within the clinical biochemistry electronic results management system was conducted to identify all TDM tests performed between 01/01/2018 and 31/12/2018. Descriptive analysis outcomes included the number of samples received, processed, overall testing population, service utilisation by Health Board, number and results of TDM tests performed per patient. TDM results were interpreted according to published guidance on the service webpage and comparison was made with previously published data (2).

Results: 3609 specimens were received for testing, from 13 of the 14 Scottish Health Boards. 3561 drug level (DL) tests were performed; 1786IFX, 1775 ADL. 2717 total antidrug anti-body (TABT) tests and 681 free antidrug anti-body tests (FABT) were performed according to service protocol. 2791 individuals had one or more TDM tests during the 12-month period, of whom 541 were tested twice or more (range 2-5).

Table 1. IFX \& ADL DL, TABT and FABT results by category as defined in service guidance $(\mathrm{AU} / \mathrm{ml}=$ Arbitrary Units/ml)

\begin{tabular}{|c|c|c|c|c|}
\hline & & INFLIXIMAB & ADALIMUMAB & \\
\hline \multirow[t]{3}{*}{$\begin{array}{l}\text { Drug level } \\
\text { by category }\end{array}$} & $\begin{array}{l}\text { Supratherapeutic DL > } \\
8 \mathrm{mcg} / \mathrm{ml}\end{array}$ & $546(30.6 \%)$ & $708(39.9 \%)$ & $\begin{array}{l}\text { Supratherapeutic } \\
\mathrm{DL}>10 \mathrm{mcg} / \mathrm{ml}\end{array}$ \\
\hline & $\begin{array}{l}\text { Therapeutic DL } \\
\geq 3<8.1 \mathrm{mcg} / \mathrm{ml}\end{array}$ & $738(41.3 \%)$ & $636(35.8 \%)$ & $\begin{array}{l}\text { Therapeutic DL } \\
\geq 5<10.1 \mathrm{mcg} / \mathrm{ml}\end{array}$ \\
\hline & $\begin{array}{c}\text { Sub-therapeutic DL }< \\
3 \mathrm{mcg} / \mathrm{ml}\end{array}$ & $502(28.1 \%)$ & $431(24.3 \%)$ & $\begin{array}{l}\text { Sub-therapeutic DL } \\
<5 \mathrm{mcg} / \mathrm{ml}\end{array}$ \\
\hline $\begin{array}{l}\text { TABT by } \\
\text { category }\end{array}$ & Negative (<10 AU/ml) & $791(54.2 \%)$ & 905 (71.9\%) & $\begin{array}{l}\text { Negative }(<10 \\
\quad \mathrm{AU} / \mathrm{ml})\end{array}$ \\
\hline
\end{tabular}


Table 1. IFX \& ADL DL, TABT and FABT results by category as defined in service guidance $(\mathrm{AU} / \mathrm{ml}=$ Arbitrary Units $/ \mathrm{ml})]$

\begin{tabular}{lcccc}
\hline & & INFLIXIMAB & ADALIMUMAB & \\
\hline \multirow{2}{*}{ FABT by } & Positive $(>10 \mathrm{AU} / \mathrm{ml})$ & $668(45.8 \%)$ & $353(28.1 \%)$ & Positive $(>10 \mathrm{AU} / \mathrm{ml})$ \\
category & Negative $(<5 \mathrm{AU} / \mathrm{ml})$ & $376(82.8 \%)$ & $176(77.6 \%)$ & Negative $(<10$ \\
& Positive $(>5 \mathrm{AU} / \mathrm{ml})$ & $78(17.2 \%)$ & $51(22.4 \%)$ & Positive $(>10 \mathrm{mU} / \mathrm{ml})$ \\
\hline
\end{tabular}

Conclusion: TDM has been enthusiastically embraced. It is estimated that > $50 \%$ of individuals treated with IFX or ADL have been tested at least once in the first year. DL results were found to be similar to previously published data, as were rates of antibody positivity. The large volume of data generated by the service may provide additional evidence regarding the utility of TDM in predicting clinical response. Next steps are to conduct a comparative effectiveness analysis where proactive vs reactive TDM testing strategies will be compared, with the primary outcome measure being the proportions of patients with secondary loss of response.

References:

[1] Scottish Biologic therapeutic Drug Monitoring Service https://www. nhsggc.org.uk/about-us/professional-support-sites/biochemistry/ biological-therapy-monitoring/

[2] Jani, M. Et al (2015), Clinical Utility of Random Anti-Tumor Necrosis Factor Drug-Level Testing and Measurement of Antidrug Antibodies on the LongTerm Treatment Response in Rheumatoid Arthritis. Arthritis \& Rheumatology, 67: 2011-2019. doi:10.1002/art.39169

Acknowledgments: Biogen $\mathrm{GmbH}$ contributed partial funding for this research. Authors had full editorial control and approval of all content

Disclosure of Interests: Jonathan MacDonald: None declared, Martin Perry Grant/research support from: Grifols, Abbvie, Sandoz unrestricted educational grant, Consultant of: Abbvie, Gilead, Celltrion Advisory Board, Speakers bureau: Sandoz, Peter Galloway: None declared, John-Paul Seenan: None declared, Alan Dunlop: None declared

DOI: 10.1136/annrheumdis-2020-eular.2320

\section{AB1187 TREATMENT ADHERENCE: WHAT ABOUT THE RHEUMATOLOGIST?}

R. Pineda-Sic ${ }^{1}$, M. M. Castañeda-Martínez ${ }^{1}$, I. D. J. Hernandez-Galarza ${ }^{1}$, E. I. Guevara Elizondo ${ }^{1}$, D. E. Flores Alvarado ${ }^{1}$, G. Serna-Peña ${ }^{1}$, I. J. ColungaPedraza', D. Á. Galarza-Delgado'. ' Universidad Autónoma de Nuevo Léon, Monterrey, Nuevo León, Mexico

Background: Adherence to medications among patients with rheumatic diseases is often suboptimal. ${ }^{1}$ Adherence to treatment has been described to be affected by several factors. ${ }^{2}$ The rheumatologist plays a crucial role in influencing adherence behavior by addressing perceptions about medication, providing information, and establishing trust in the treatment plan. ${ }^{3}$ There is no record of attitudes and thoughts of Mexico's rheumatologists about adherence to medication. Objectives: To know the rheumatologist's attitudes regarding treatment adherence in follow up consultation.

Methods: Descriptive, cross sectional study. Rheumatologists from across the country were invited to respond an electronic survey created with Google Forms, link was sent by Whatsapp ${ }^{\circledR}$ message, responses were anonymous. The survey was constructed taking into account the main barriers of adherence related to the doctor. Seven questions were created, from one to six were multiple selections and the seven were open question 1.Where do you practice medicine? 2.Do you ask all your patients about adherence medication? 3.If your answer was positive, do you ask individually for each drug? 4. How long do you spend on explaining: side effects, benefits, and mechanisms of action of drugs? 5 Do you discuss available treatment options with your patients to decide one? 6 . What's the definition of adherence? 7.Which activities can the doctor do to improve adherence to their patients?

Results: Data were collected from 158 rheumatologists who completed the survey. Regarding the question where they practice medicine, $19.5 \%$ answered they work in public medical institutions, $31.8 \%$ do private practice and $48.7 \%$ work in both of them, $88.3 \%$ answered correctly adherence definition, $93 \%$ of rheumatologists ask for adherence to medication in the follow up consultation and only $86.1 \%$ do it individually for each medication, $97.4 \%$ discuss therapeutic options with their patients. The time used to explain treatment is presented in Figure 1. The interventions considered by rheumatologists to increase adherence are reported in Table 1.
Table 1 Interventions considered by rheumatologists to increase adherence

Patient education (in follow up consultation, conferences, pamphlets)

Develop rapport with patient. ("be accessible," "answer questions" "make the patient part of" don't be paternalistic or authoritarian")

Adherence measure (Use the available method, questionnaires, self-report, drug levels, electronic pillbox, pill count, etc. "Don't matter which one, measure it! ")

Interventions for no adherence reasons (phone calls, text messages, telephone alarms) fixed schedules for each medication, cognitive-behavioral therapy, access to medications) Family support network

Presented in order to frequencies and grouped by topic

Figure 1

Time used by rheumatologists to explain treatment in follow up consultation

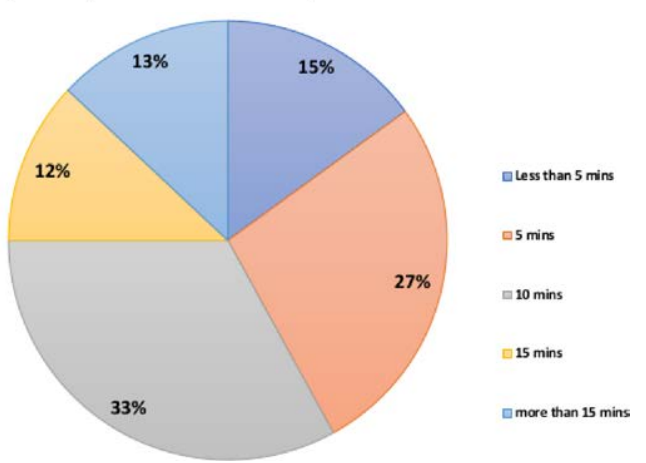

Conclusion: Rheumatologists ask for adherence medication but more than half use a limited amount of time to explain about medication, nevertheless, they think that patient education is the best intervention to increase adherence.

References:

[1] Pasma, Annelieke et.al Facilitators and Barriers to Adherence in the Initiation Phase of Disease modifying Antirheumatic Drug (DMARD) Use in Patients with Arthritis Who Recently Started Their First DMARD Treatment, The Journal of Rheumatology (2013) DOI:10.3899/jrheum.140693.

[2] M.F. M. Improving treatment adherence in patients with rheumatoid arthritis: What are the options? Int J Clin Rheumtol. 2015;10(5):345-56.

[3] Voshaar et al. Barriers and facilitators to disease modifying antirheumatic drug use in patients with inflammatory rheumatic diseases: a qualitative theory-based study. BMC Musculoskeletal Disorders (2016) 17:442 DOI 10.1186/s12891-016-1289-z

Disclosure of Interests: None declared

DOI: 10.1136/annrheumdis-2020-eular.4011

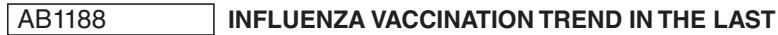 DECADE AND FACTORS INFLUENCING THE RATE OF INFLUENZA VACCINATION IN CHRONIC INFLAMMATORY ARTHRITIS IN THE ITALIAN REGION OF FRIULI VENEZIA GIULIA (2006-2018)}

L. Quartuccio ${ }^{1}$, A. Zabotti ${ }^{2}$, G. De Marchi ${ }^{2}$, T. Gallo ${ }^{3}$, S. De Vita ${ }^{1}$, F. Valent ${ }^{4}$.

${ }^{1}$ Clinic of Rheumatology, Department of Medicine, Academic Hospital

"Santa Maria della Misericordia”, ASUI, Udine, Italy, Udine, Italy; ${ }^{2}$ Clinic of Rheumatology, Academic Hospital "Santa Maria della Misericordia”, ASUI, Udine, Italy, Udine, Italy; ${ }^{3}$ Department of Prevention, ASUFC, Udine, Italy, Udine, Italy; ${ }^{4}$ Institute of Epidemiology, Academic Hospital "Santa Maria della Misericordia", ASUI, Udine, Italy, Udine, Italy

Background: vaccination is one of the most important medical intervention to prevent infectious complications in population at risk. EULAR recommendations for vaccination of patients suffering from autoimmune inflammatory rheumatic diseases (AIIRD) have been recently updated (1).

Objectives: to verify the level of coverage of the influenza vaccination in a local population of patients suffering from rheumatoid arthritis (RA), psoriatic arthritis (PsA) or ankylosing spondylitis (AS).

Methods: integration of the information coming from many administrative databases were used to this end. The Regional Health Information System of Friuli Venezia Giulia was used as the source of information for this retrospective cohort study. Patients were residents in Friuli Venezia Giulia and they had to carry the exemption code for RA, or PsA, or AS and at least one prescription of a 